Published in final edited form as:

Cancer Causes Control. 2010 July ; 21(7): 1147-1154. doi:10.1007/s10552-010-9531-8.

\title{
A case-control study of tobacco use and other non-occupational risk factors for lymphoma subtypes defined by $t(14 ; 18)$ translocations and bcl-2 expression
}

\author{
Cindy M. Chang ${ }^{1}$, Jane C. Schroeder ${ }^{2}$, Andrew F. Olshan ${ }^{2}$, Cherie H. Dunphy ${ }^{3}$, Wen-Yi \\ Huang $^{4}$, Ralph S. Baric ${ }^{2}$, Kathleen Conway ${ }^{2}$, James R. Cerhan ${ }^{5}$, Charles F. Lynch ${ }^{6}$, \\ Nathaniel Rothman ${ }^{4}$, Kenneth P. Cantor ${ }^{4}$, and Aaron Blair ${ }^{4}$ \\ ${ }^{1}$ Infections and Immunoepidemiology Branch, National Cancer Institute, Rockville, MD \\ ${ }^{2}$ Department of Epidemiology, School of Public Health, University of North Carolina at Chapel Hill, \\ Chapel Hill, NC \\ ${ }^{3}$ Department of Pathology and Laboratory Medicine, School of Medicine, University of North \\ Carolina at Chapel Hill, Chapel Hill, NC \\ ${ }^{4}$ Occupational and Environmental Epidemiology Branch, National Cancer Institute, Bethesda, MD \\ ${ }^{5}$ Health Sciences Research, Mayo Clinic, Rochester, MN \\ ${ }^{6}$ Department of Epidemiology, University of lowa, lowa City, IA
}

\section{Abstract}

Objective-We re-evaluated reported associations between tobacco use and other factors and non-Hodgkin lymphoma (NHL) $t(14 ; 18)$-subtypes based on fluorescence in situ hybridization (FISH) assays believed to be more sensitive than polymerase chain reaction (PCR), previously used for detecting $\mathrm{t}(14 ; 18)$.

Methods-Commercial FISH assays and bcl-2 immunostaining were performed on paraffin sections to determine $\mathrm{t}(14 ; 18)$ and bcl-2 case-subtypes. Polytomous logistic regression models estimated associations between NHL case-subtypes (versus 1,245 population-based controls) and tobacco use as well as other factors.

Results-Adjusting for age, state, and proxy status, $t(14 ; 18)$-negative NHL was associated with any tobacco use (vs. no tobacco use, $\mathrm{OR}=1.9,95 \% \mathrm{CI}=1.0-3.5$ ), including current smoking (vs. no cigarette use, $\mathrm{OR}=1.9,95 \% \mathrm{CI}=1.1-3.2)$. Tobacco exposures were not clearly associated with $\mathrm{t}(14 ; 18)$-positive NHL or bcl-2 case-subtypes. Hair dye use and family history of a hemolymphatic cancer were associated with $\mathrm{t}(14 ; 18)$-negative NHL, but the number of exposed cases was small.

Conclusions-The association between $\mathrm{t}(14 ; 18)$-negative NHL and cigarette smoking was unexpected given previous evidence of associations between smoking and follicular lymphoma (which is largely $t(14 ; 18)$-positive). Future studies characterizing additional molecular characteristics of $\mathrm{t}(14 ; 18)$-negative NHL may help determine whether the association with smoking may have been causal versus an artifact of chance or bias.

\section{Keywords}

bcl-2; epidemiology; lymphoma; molecular genes; non-Hodgkin; tobacco; translocation (genetics); FISH; t(14;18) 


\section{Introduction}

It has been suggested that associations observed between follicular lymphoma and smoking may reflect an effect of smoking on the frequency or prevalence of $t(14 ; 18)$-positive lymphocytes which results in the overexpression of the antiapoptic protein bcl-2 (1). A previous analysis in which polymerase chain reaction (PCR) assays were run to detect $\mathrm{t}(14 ; 18)$ in archival tumor samples from a subset of Iowa and Minnesota NHL cases in the Factors Affecting Rural Men (FARM) case-control study (2) did not find a clear association between smoking and $t(14 ; 18)$-NHL case-subtypes, but nondifferential misclassification of cases may have occurred. Although PCR is believed to be a reasonably specific method for detecting $\mathrm{t}(14 ; 18)$ in archival tumor samples, sensitivity is limited because assays fail to detect translocations with BCL2 breakpoints that occur outside of regions bounded by the PCR primers used. Consequently, approximately $15-25 \%$ of $\mathrm{t}(14 ; 18)$-positive cases may be misclassified as $\mathrm{t}(14 ; 18)$-negative based on PCR [3].

In contrast, fluorescence in situ hybridization (FISH) assays can detect translocations with more widely dispersed breakpoints than PCR. Studies comparing $t(14 ; 18)$ assays run on the same samples have shown that FISH consistently detects more $t(14 ; 18)$-positive samples than PCR (3-8). In addition, use of FISH allows in situ localization of $t(14 ; 18)$ to neoplastic lymphocytes, thus decreasing the likelihood of falsely classifying lymphomas as $t(14 ; 18)$ positive due to amplification of rare non-neoplastic $t(14 ; 18)$-positive lymphocytes (9-11).

Therefore, we re-evaluated associations between $\mathrm{t}(14 ; 18)$-positive and -negative case subtypes and tobacco use, family history and other factors among FARM study participants after using FISH assays to re-classify the $t(14 ; 18)$ status of archival tumor samples that were previously classified based on PCR (2). In order clarify whether associations may be due to $t(14 ; 18)$ or bcl-2 expression which can be caused by multiple mechanisms (12), we estimated associations with lymphoma subtypes defined by bcl-2 expression based on immunohistochemistry.

\section{Materials and methods}

\section{Study population and exposure assessment}

The FARM study is a population-based study of incident, pathologically confirmed hemolymphatic cancer cases in Iowa and Minnesota men that was designed to evaluate the possible role of agricultural factors in the origin of NHL. The study population and methods were previously described in detail (13-14). Briefly, cases and controls were white male residents of Iowa or non-metropolitan areas of Minnesota. Cases diagnosed with a hemolymphatic cancer between 1980 and 1983 at age 30 or older were identified through hospital and pathology laboratory records (in Minnesota) and the Iowa State Health Registry. NHL was confirmed for 622 cases based on pathology review. Controls, identified using random digit dialing, Medicare files, and death certificate files, included 1,245 white males without a history of hemolymphatic cancer who were age 30 or older at enrollment. Controls were frequency-matched to cases by age and state. In addition, cases and controls were frequency matched on vital status, so that study interviews with next-of-kin proxies were conducted for one-third of cases and controls. Detailed information including past or current tobacco use, type, frequency and duration was obtained through in-person structured interviews administered between 1981 and 1984. Response rates were $86 \%$ for cases and $77-79 \%$ for controls.

\section{Case-subtypes}

Archival paraffin-embedded tumor blocks were successfully retrieved for 248 FARM study NHL cases (40\% of all NHL cases in the original study) (2). Based on pathology review of 
the 10-micron sections cut from archival tumor blocks, cases were classified based on the Revised European American Lymphoma (REAL) classification scheme (15). For the present study we describe case subtypes using updated terminology that is generally consistent with the current WHO lymphoma classification scheme (16-17).

The methods for the PCR, FISH, and bcl-2 immunostaining have been previously described in detail $(2,16)$. In brief, the $t(14 ; 18)-P C R$ assays were performed on DNA extracted from 10-micron tumor sections using a consensus primer corresponding to a conserved portion of the J segment of the IGH gene on chromosome 14 (5'-ACCTGAGGAGACGGTGAGC-3') and a second primer corresponding to the $B C L 2$ major breakpoint region (MBR) on chromosome 18 (MBR1: 5'-GAGAGTTGCTTTACGTG-GCCTG-3') which includes $40-60 \%$ of $B C L 2$ breakpoints involved in $\mathrm{t}(14 ; 18)$. Translocation-negative samples were subjected to a second PCR reaction with the IGH consensus primer and a second $B C L 2$ primer 360 base pairs upstream of the MBR primer (MBR2: $5^{\prime}$ -

CGCTTGACTCCTTTACGTGCTG-3'). Amplification was confirmed using radio-labeled probes that hybridized to DNA adjacent to each $B C L 2$ primer site. Amplification of a 175base pair segment of the hemoglobin beta $(H B B)$ gene served as an internal positive control.

Commercially available FISH $\mathrm{t}(14 ; 18)$ assays were run on 5-micron tumor sections stored at $4^{\circ} \mathrm{C}$ prior to use (Vysis/Abbot Molecular, Des Plaines, IL). $\mathrm{t}(14 ; 18)$ translocations were identified using the LSI ${ } I G H / B C L 2$ Dual Color, Dual Fusion Translocation Probe. $t(14 ; 18)$ assays were scored by two investigators on 166 cases (16). Cases were classified as translocation-positive if more than $30 \%$ of cells showed abnormal signal patterns.

Preconsensus concordance was $73 \%$ for FISH (including unreadable cases). Samples with discordant results were assigned a consensus classification based on a joint review.

bcl-2 immunostaining was performed on tumor sections from 229 cases using a mouse monoclonal antibody corresponding to bcl-2 amino acids 41-54 (clone 124; Dako Denmark A/S, Copenhagen, Denmark). Scored by two investigators, cases were classified as bcl-2 positive if more than $20 \%$ of cells showed cytoplasmic staining. Preconsensus concordance was $92 \%$ for bcl-2, and discordant cases were reviewed and assigned a consensus classification.

\section{Data analysis}

Analyses including models for case-subtypes were performed using data from 227 cases with complete FISH, PCR, and immunostaining data. Use of any tobacco and specific tobacco products (cigarettes, cigars, pipe tobacco, chewing tobacco, snuff) was defined as daily use for at least 3 months. Cigarette smoking was categorized according to past (stopped more than 2 years before interview) or current smoking (within 2 years of interview), average intensity of use ( $0,1-10,11-20,>20$ cigarettes per day), age of first use (18 or less, over age 18 ), and pack-years $(0,>0-20,>20-40,>40)$. In addition, we estimated associations between NHL case-subtypes and other putative NHL risk factors including, family history of hemolymphatic cancer (in a first- or second-degree relative), hair dye use (at least once a month for at least one year, or occupational exposure to hair dyes on any job held for 1 or more years), occupation as farmer (worked on a farm for 6 continuous months or longer since the age 18), weekly alcohol use (drank beer, wine or hard liquor weekly for at least one year), education ( $<=12$ years, $>12$ years), and marital status (married/widowed, divorced/separated, never married).

Case-only (case-case) analyses were performed to determine whether estimates were comparable between molecular subtypes, including $t(14 ; 18)$-positive vs. -negative casesubtypes and bcl-2 positive vs. -negative case-subtypes using unconditional logistic regression models (SAS ${ }^{\circledR}$ version 9.1) (18). Case-subtype: control associations were 
estimated by polytomous logistic regression models with the expectation-maximization (EM) algorithm used to reduce potential bias caused by missing case-subtype data (for cases for whom tumor blocks could not be retrieved or that were not successfully assayed) as previously described (19) (Stata release 9.0, (20)).

All models included the matching factors state (Minnesota vs. Iowa), age at diagnosis (coded using upper and lower tail-restricted quadratic splines), and proxy status. Covariates examined were factors associated with NHL in past studies (e.g. alcohol use (21), family history of hemolymphatic (HLP) cancer (22) and farming (23) as well as demographic factors (age (24) and education (24-25)). No confounding was evident based a 0.15 or greater change in the beta coefficient of the main exposure variable when the potential confounder was removed from the model; therefore, final models included the matching factors only.

Dose-response was evaluated for pack-years and cigarettes per day based on an informal examination of point estimates for categorical variables and on trend test $p$-values derived by modeling pack-years of smoking and cigarettes per day as continuous variables among smokers only.

\section{Results}

Among 152 successfully assayed cases, $54 \%$ or 82 cases were t(14;18)-positive based on FISH assays. Among 206 successfully assayed cases by IHC, 157 cases were bcl-2-positive $(76 \%)$.

Any tobacco use was common in the study population, with only $23 \%$ of 1245 controls and $17 \%$ of 151 cases with sample successfully assayed with FISH reporting never use of tobacco products. Any tobacco use was associated with $\mathrm{t}(14 ; 18)$-negative NHL $(\mathrm{OR}=1.9$, $95 \% \mathrm{CI}=1.0-3.5$ ) (Table 1). $\mathrm{t}(14 ; 18)$-negative NHL was associated with any cigar use (vs. no cigar use, $\mathrm{OR}=1.6,95 \% \mathrm{CI}=1.0-2.6$ ), use of cigarettes only (vs. no tobacco use, $\mathrm{OR}=2.0,95 \% \mathrm{CI}=1.0-3.7$ ), use of cigarettes and other tobacco use (vs. no tobacco use, $\mathrm{OR}=2.1,95 \% \mathrm{CI}=1.1-3.9$ ), and both current and former smoking (vs. no cigarette use, $\mathrm{OR}=1.7,95 \% \mathrm{CI} 0.9-2.9$ and $\mathrm{OR}=1.9,95 \% \mathrm{CI}=1.1-3.2$, respectively). Having smoked 40 or more pack-years (vs. no cigarette use, $\mathrm{OR}=2.0,95 \% \mathrm{CI}=1.2-3.4$ ), all categories for number of cigarettes smoked per day, and both age categories for first cigarette use were also associated with $\mathrm{t}(14 ; 18)$-negative NHL, but neither increasing pack-years of smoking nor increasing cigarettes per day were associated with the outcome when modeled as a continuous variables among smokers $(\mathrm{p}=0.4$ and $\mathrm{p}=0.9$, respectively).

For $t(14 ; 18)$-positive NHL, we found that associations with cigarette smoking exposures were inverse or null (OR's 0.6-1.0), with the strongest inverse association noted for any cigarette use (vs. no cigarette use, $\mathrm{OR}=0.6,95 \% \mathrm{CI}=0.3-1.0$ ). A modest positive association with $\mathrm{t}(14 ; 18)$-positive NHL was estimated for tobacco use other than cigarette smoking (vs. no tobacco use, $\mathrm{OR}=1.6,95 \% \mathrm{CI}=0.9-2.9)$. In addition, there was evidence of a stronger association when chewing tobacco use began before age 18 based on a small number of exposed cases $(\mathrm{OR}=2.1,95 \% \mathrm{CI}=0.9-4.5,6$ exposed cases) than after age $18(\mathrm{OR}=1.2,95 \%$ $\mathrm{CI}=0.6-2.3,7$ exposed cases). Case-case effect estimates for $\mathrm{t}(14 ; 18)$-positive vs. $\mathrm{t}(14 ; 18)$ negative NHL were often below the null for cigarette exposures (Table 1).

No tobacco exposures were clearly associated with either bcl-2 case-subtype. Consistent with these findings, case-case estimates for bcl-2 positive NHL versus bcl-2 negative NHL were close to null or very imprecise (Table 2). 
Estimated associations for other non-occupational exposures and $t(14 ; 18)$ case-subtypes were generally consistent with estimates made for $t(14 ; 18)$ case-subtypes classified based on PCR (Table 3) (2). Consistent with the PCR results, having a first or second-degree relative with hemolymphatic cancer was associated with FISH-defined $t(14 ; 18)$-negative NHL $(\mathrm{OR}=3.0,95 \% \mathrm{CI}=1.8-5.0)$, but not $\mathrm{t}(14 ; 18)$-positive lymphoma $(\mathrm{OR}=0.9,95 \%$ $\mathrm{CI}=0.4-2.3)$. However, a positive family history was associated with both bcl-2 negative $(\mathrm{OR}=2.5,95 \% \mathrm{CI}=1.2-5.1)$ and bcl-2 positive $(\mathrm{OR}=1.6,95 \% \mathrm{CI}=1.0-2.6)$ case-subtypes. In contrast to the PCR results which showed a similarly positive association between hair dye use and both $\mathrm{t}(14 ; 18)$ case-subtypes, FISH results suggest a weaker association between hair dye use and $\mathrm{t}(14 ; 18)$-positive $\mathrm{NHL}(\mathrm{OR}=1.3,95 \% \mathrm{CI}=0.6-2.6)$ than $\mathrm{t}(14 ; 18)$-negative lymphoma $(\mathrm{OR}=2.9,95 \% \mathrm{CI}=1.6-5.0)$. IHC results suggest a slightly stronger association between hair dye use and bcl-2 positive NHL ( $\mathrm{OR}=2.2,95 \% \mathrm{CI}=1.4-3.4)$, than for bcl-2 negative NHL ( $\mathrm{OR}=1.4,95 \% \mathrm{CI}=0.5-3.8)$. However, all estimates were based on small numbers of exposed cases in each case-subgroup.

\section{Discussion}

Using FISH assays, we detected a number of $\mathrm{t}(14 ; 18)$-positive cases that had been previously classified as $t(14 ; 18)$-negative based on PCR which has been described previously (16). Based on the numbers in our previous study and using FISH as the gold standard, PCR has a sensitivity of $56 \%$ and specificity of $88 \%$ for detecting $t(14 ; 18)$.

We noted a positive association between FISH-defined $t(14 ; 18)$-negative NHL and tobacco use that was not apparent in our previous analysis of $\mathrm{t}(14 ; 18)$-NHL based on PCR assays. The differences between associations reported for $t(14 ; 18)$ subtypes classified using FISH and associations previously reported for $\mathrm{t}(14 ; 18)$ subtypes classified using PCR may reflect misclassification of cases by PCR. Differences may also reflect the instability of point estimates based on small numbers of cases, since the case series classified using the two approaches were not exactly the same (specifically, 227 cases were included in both studies and, 11 were included in the PCR study). However, estimated associations with $t(14 ; 18)$ subtypes classified according to the original PCR assay were comparable to those previously reported for PCR-based subtypes in this study population (data not shown). Although all were performed on paraffin-embedded tumor sections, the number of successfully assayed cases by IHC $(n=206)$ was greater than that for FISH $(n=152)$ or PCR $(n=170)$. These results are likely to reflect differences in the assays themselves rather than sampling error or sample quality.

Our findings on smoking were consistent with those of the Nebraska t(14;18)-NHL study based on tissue microarrays (TMAs) run with FISH (26). They reported an association between smoking and $\mathrm{t}(14 ; 18)$-negative $\mathrm{NHL}(\mathrm{OR}=1.9,95 \% \mathrm{CI}=1.1-3.3)$, but the association was specific to women with no $t(14 ; 18)$ case-subtype associations evident among men. The Nebraska study investigators reported that a positive family history of a hematopoietic cancer was associated with both $\mathrm{t}(14 ; 18)$-subtypes (OR's 1.9-2.2) among both men and women, while only $\mathrm{t}(14 ; 18)$-negative NHL was associated with family history in our study. Finally, we found an association between hair-dye use and $t(14 ; 18)$-negative NHL, while hair-dye use was not associated with either case-subtype in the Nebraska study. We noted a higher proportion of $\mathrm{t}(14 ; 18)$-positive cases among all cases (53\% vs. $38 \%$ ) and among follicular lymphomas ( $81 \%$ vs. $67 \%$ ) than those in the Nebraska study, which would be consistent with differences in the prevalence of $t(14 ; 18)$-NHL between the two study populations or with reduced sensitivity due to the use of TMAs based on four representative 0.6-mm cores from each biopsy in the Nebraska study. 
The association between cigarette smoking and $t(14 ; 18)$-negative NHL was unexpected, given results of several previous studies that found a positive association between smoking and follicular lymphoma (27-33), which is largely $\mathrm{t}(14 ; 18)$-positive (14-21), as well as prior evidence of increased $t(14 ; 18)$ in the peripheral blood lymphocytes of smokers compared with non-smokers $(1,34)$. A previous analysis of tobacco use with all 622 FARM study cases also showed unclear results. In the entire FARM study population, current smoking was modestly associated with all lymphoma subtypes $(\mathrm{OR}=1.5,95 \% \mathrm{CI}=1.1-2.0)$, but it was not more strongly associated with follicular lymphoma (OR=1.4, 95\% CI=0.9-2.3) (35).

Overall, bcl-2 expression assays did not clarify the nature of the subtype-specific association between $t(14 ; 18)$-negative NHL and cigarette smoking. We did not see evidence of associations between smoking and bcl- 2 negative NHL, which suggests that the associations observed with $\mathrm{t}(14 ; 18)$-negative NHL were not a function of bcl-2 negative status.

Strengths of the study include use of a large population-based control group (selected through RDD, Medicare files, and death certificates with a nearly $80 \%$ response rate), the availability of detailed exposure data from both cases and controls, the use of FISH to determine $t(14 ; 18)$-subtypes, and the availability of bcl-2 expression data in addition to information on $\mathrm{t}(14 ; 18)$. Among the limitations, cases included in the current analysis were limited to those with archival tumor material and successful FISH assays, thus less than 25\% of the 622 original FARM study NHL cases were successfully assigned a case-subtype. The majority of missing cases were from Minnesota (55\% of 470 total missing), consequently, case-subtype:control estimates may have been biased if missing outcome data were associated with exposures. To address this, we used an EM-based method to impute missing case-subtype data, as previously described; however, bias due to missing data cannot be ruled out [20]. Recall bias and misclassification of exposures are potential concerns, but are not likely to be differential between case-subtypes. Additionally, self-reported smoking is generally accurate except when considered socially undesirable (i.e. in pregnancy), which does not apply to this study population (36). Generalizability of the results may be limited due to the restriction to white, rural males in this study. However, the prevalence of smoking in the study population was comparable to that of US males in the 1980s. Among controls, the prevalence of any (past or current) cigarette smoking was $66 \%$ overall, $60 \%$ in farmers and $74 \%$ in non-farmers. These estimates are comparable, if not lower for farmers, to the prevalence of any smoking in the same birth cohort of US men in 1980 (70-80\%) (37). Thus, while we cannot rule out the possibility that the findings may have been specific to this study population, smoking in the study population did not appear to differ substantially from expectations for a rural population. Finally, uncontrolled confounding is always a possibility, particularly given that few risk factors for NHL have been identified.

In summary, our data suggest that smoking may be associated with $\mathrm{t}(14 ; 18)$-negative NHL. In order to clarify the role of smoking and other potential risk factors in the etiology of $t(14 ; 18)$ NHL, subtypes defined by molecular characteristics in addition to $t(14 ; 18)$ should be pursued. Future studies should incorporate histologic subtypes assigned in clinical settings where the role of molecular analyses is increasing in the routine pathologic evaluation of lymphoma cases (38). Alternatively, improved methods to estimate the incidence and prevalence of $\mathrm{t}(14 ; 18)$ translocations in the peripheral blood lymphocytes of people without cancer may help clarify whether or how smoking and other exposures influence the pathogenesis of $\mathrm{t}(14 ; 18)$-positive lymphomas (39-41).

\section{Acknowledgments}

This study was supported in part by the UNC Lineberger Comprehensive Cancer Center (Population Sciences Research Award), the Intramural Program of the National Institutes of Health (Environmental Health Sciences (P30ES10126)) and the National Cancer Institute (R03 CA71617-01). Special thanks to Sophia Wang and Charles 
Rabkin from the National Cancer Institute, David W. Cowan, Stephen Oglesbee, Georgette Dent, and Boyd Yount from UNC-Chapel Hill, Clarice Weinberg from the National Institute of Environmental Health Sciences, and Paige Tolbert from Emory University.

\section{References}

1. Bell DA, Liu Y, Cortopassi GA. Occurrence of bcl-2 oncogene translocation with increased frequency in the peripheral blood of heavy smokers. J Natl Cancer Inst 1995;87:223-4. [PubMed: 7707410]

2. Schroeder JC, Olshan AF, Baric R, Dent GA, Weinberg CR, Yount B, et al. A case-control study of tobacco use and other non-occupational risk factors for $\mathrm{t}(14 ; 18)$ subtypes of non-Hodgkin's lymphoma (United States). Cancer Causes Control 2002;13:159-68. [PubMed: 11936822]

3. Barrans SL, Evans PA, O'Connor SJ, Owen RG, Morgan GJ, Jack AS. The detection of t $(14 ; 18)$ in archival lymph nodes: development of a fluorescence in situ hybridization (FISH)-based method and evaluation by comparison with polymerase chain reaction. J Mol Diagn 2003;5:168-75. [PubMed: 12876207]

4. Belaud-Rotureau MA, Parrens M, Carrere N, Turmo M, Ferrer J, de Mascarel A, et al. Interphase fluorescence in situ hybridization is more sensitive than BIOMED-2 polymerase chain reaction protocol in detecting IGH-BCL2 rearrangement in both fixed and frozen lymph node with follicular lymphoma. Hum Pathol 2007;38:365-72. [PubMed: 17134735]

5. Einerson RR, Kurtin PJ, Dayharsh GA, Kimlinger TK, Remstein ED. FISH is superior to PCR in detecting $\mathrm{t}(14 ; 18)(\mathrm{q} 32 ; \mathrm{q} 21)-\mathrm{IgH} / \mathrm{bcl}-2$ in follicular lymphoma using paraffin-embedded tissue samples. Am J Clin Pathol 2005;124:421-9. [PubMed: 16191511]

6. Godon A, Moreau A, Talmant P, Baranger-Papot L, Genevieve F, Milpied N, et al. Is t $(14 ; 18)$ (q32; 21 ) a constant finding in follicular lymphoma? An interphase FISH study on 63 patients. Leukemia 2003;17:255-9. [PubMed: 12529690]

7. Poetsch M, Weber-Matthiesen K, Plendl HJ, Grote W, Schlegelberger B. Detection of the $t(14 ; 18)$ chromosomal translocation by interphase cytogenetics with yeast-artificial-chromosome probes in follicular lymphoma and nonneoplastic lymphoproliferation. J Clin Oncol 1996;14:963-9. [PubMed: 8622046]

8. Streubel B, Scheucher B, Valencak J, Huber D, Petzelbauer P, Trautinger F, et al. Molecular cytogenetic evidence of $\mathrm{t}(14 ; 18)(\mathrm{IGH} ; \mathrm{BCL} 2)$ in a substantial proportion of primary cutaneous follicle center lymphomas. Am J Surg Pathol 2006;30:529-36. [PubMed: 16625101]

9. Cook JR. Paraffin section interphase fluorescence in situ hybridization in the diagnosis and classification of non-hodgkin lymphomas. Diagn Mol Pathol 2004;13:197-206. [PubMed: 15538109]

10. Medeiros LJ, Carr J. Overview of the role of molecular methods in the diagnosis of malignant lymphomas. Arch Pathol Lab Med 1999;123:1189-207. [PubMed: 10583924]

11. Spagnolo DV, Ellis DW, Juneja S, Leong AS, Miliauskas J, Norris DL, et al. The role of molecular studies in lymphoma diagnosis: a review. Pathology 2004;36:19-44. [PubMed: 14757555]

12. Papakonstantinou G, Verbeke C, Hastka J, Bohrer M, Hehlmann R. bcl-2 expression in nonHodgkin's lymphomas is not associated with bcl-2 gene rearrangements. Br J Haematol 2001;113:383-90. [PubMed: 11380403]

13. Blair A, Linos A, Stewart PA, Burmeister LF, Gibson R, Everett G, et al. Evaluation of risks for non-Hodgkin's lymphoma by occupation and industry exposures from a case-control study. Am J Ind Med 1993;23:301-12. [PubMed: 8427258]

14. Brown LM, Blair A, Gibson R, Everett GD, Cantor KP, Schuman LM, et al. Pesticide exposures and other agricultural risk factors for leukemia among men in Iowa and Minnesota. Cancer Res 1990;50:6585-91. [PubMed: 2208120]

15. Harris NL, Jaffe ES, Stein H, Banks PM, Chan JK, Cleary ML, et al. A revised EuropeanAmerican classification of lymphoid neoplasms: a proposal from the International Lymphoma Study Group. Blood 1994;84:1361-92. [PubMed: 8068936]

16. Chang CM, Schroeder JC, Huang WY, Dunphy CH, Baric RS, Olshan AF, et al. Non-Hodgkin lymphoma (NHL) subtypes defined by common translocations: Utility of fluorescence in situ hybridization (FISH) in a case-control study. Leuk Res. 2009 
17. Jaffe, ES.; Harris, NL.; Stein, H.; Vardiman, JW., editors. Pathology and Genetics of Tumours of Haematopoietic and Lymphoid Tissues. IARCPress; Lyon: 2001.

18. SAS. Institute Inc. SAS®: Version 9.1. SAS Institute, Inc.; Cary (NC): Copyright@2002-2003

19. Schroeder JC, Weinberg CR. Use of missing-data methods to correct bias and improve precision in case-control studies in which cases are subtyped but subtype information is incomplete. Am J Epidemiol 2001;154:954-62. [PubMed: 11700251]

20. STATA. StataCorp LP. Stata Statistical Software, 9.0 ed. College Station, TX: 2007.

21. Morton LM, Zheng T, Holford TR, Holly EA, Chiu BC, Costantini AS, et al. Alcohol consumption and risk of non-Hodgkin lymphoma: a pooled analysis. Lancet Oncol 2005;6:469-76. [PubMed: 15992695]

22. Wang SS, Slager SL, Brennan P, Holly EA, De Sanjose S, Bernstein L, et al. Family history of hematopoietic malignancies and risk of non-Hodgkin lymphoma (NHL): a pooled analysis of 10 211 cases and 11905 controls from the International Lymphoma Epidemiology Consortium (InterLymph). Blood 2007;109:3479-88. [PubMed: 17185468]

23. Keller-Byrne JE, Khuder SA, Schaub EA, McAfee O. A meta-analysis of non-Hodgkin's lymphoma among farmers in the central United States. Am J Ind Med 1997;31:442-4. [PubMed: 9093659]

24. Alexander DD, Mink PJ, Adami HO, Chang ET, Cole P, Mandel JS, et al. The non-Hodgkin lymphomas: a review of the epidemiologic literature. Int J Cancer 2007;120(Suppl 12):1-39. [PubMed: 17405121]

25. Cantor KP, Fraumeni JF Jr. Distribution of non-Hodgkin's lymphoma in the United States between 1950 and 1975. Cancer Res 1980;40:2645-52. [PubMed: 6992990]

26. Chiu BC, Dave BJ, Blair A, Gapstur SM, Chmiel JS, Fought AJ, et al. Cigarette smoking, familial hematopoietic cancer, hair dye use, and risk of $\mathrm{t}(14 ; 18)$-defined subtypes of non-Hodgkin's lymphoma. Am J Epidemiol 2007;165:652-9. [PubMed: 17204518]

27. Herrinton LJ, Friedman GD. Cigarette smoking and risk of non-Hodgkin's lymphoma subtypes. Cancer Epidemiol Biomarkers Prev 1998;7:25-8. [PubMed: 9456239]

28. Morton LM, Hartge P, Holford TR, Holly EA, Chiu BC, Vineis P, et al. Cigarette smoking and risk of non-Hodgkin lymphoma: a pooled analysis from the International Lymphoma Epidemiology Consortium (interlymph). Cancer Epidemiol Biomarkers Prev 2005;14:925-33. [PubMed: 15824165]

29. Morton LM, Holford TR, Leaderer B, Boyle P, Zahm SH, Zhang Y, et al. Cigarette smoking and risk of non-Hodgkin lymphoma subtypes among women. Br J Cancer 2003;89:2087-92. [PubMed: 14647142]

30. Parker AS, Cerhan JR, Dick F, Kemp J, Habermann TM, Wallace RB, et al. Smoking and risk of non-Hodgkin lymphoma subtypes in a cohort of older women. Leuk Lymphoma 2000;37:341-9. [PubMed: 10752985]

31. Schollkopf C, Smedby KE, Hjalgrim H, Rostgaard K, Gadeberg O, Roos G, et al. Cigarette smoking and risk of non-Hodgkin's lymphoma--a population-based case-control study. Cancer Epidemiol Biomarkers Prev 2005;14:1791-6. [PubMed: 16030118]

32. Stagnaro E, Ramazzotti V, Crosignani P, Fontana A, Masala G, Miligi L, et al. Smoking and hematolymphopoietic malignancies. Cancer Causes Control 2001;12:325-34. [PubMed: 11456228]

33. Stagnaro E, Tumino R, Parodi S, Crosignani P, Fontana A, Masala G, et al. Non-Hodgkin's lymphoma and type of tobacco smoke. Cancer Epidemiol Biomarkers Prev 2004;13:431-7. [PubMed: 15006920]

34. Rauzy O, Galoin S, Chale JJ, Adoue D, Albarede JL, Delsol G, et al. Detection of t $(14 ; 18)$ carrying cells in bone marrow and peripheral blood from patients affected by non-lymphoid diseases. Mol Pathol 1998;51:333-8. [PubMed: 10193514]

35. Brown LM, Everett GD, Gibson R, Burmeister LF, Schuman LM, Blair A. Smoking and risk of non-Hodgkin's lymphoma and multiple myeloma. Cancer Causes Control 1992;3:49-55. [PubMed: 1536913] 
36. Florescu A, Ferrence R, Einarson T, Selby P, Soldin O, Koren G. Methods for quantification of exposure to cigarette smoking and environmental tobacco smoke: focus on developmental toxicology. Ther Drug Monit 2009;31:14-30. [PubMed: 19125149]

37. Shopland D, Burns D, Samet J, Gritz E. Monograph 1: Strategies to Control Tobacco Use In the United States: A Blueprint for Public Health Action In the 1990's National Cancer Institute. 1991

38. Campbell LJ. Cytogenetics of lymphomas. Pathology 2005;37:493-507. [PubMed: 16373229]

39. Baccarelli A, Hirt C, Pesatori AC, Consonni D, Patterson DG Jr. Bertazzi PA, et al. t (14;18) translocations in lymphocytes of healthy dioxin-exposed individuals from Seveso, Italy. Carcinogenesis 2006;27:2001-7. [PubMed: 16543249]

40. Bentham G, Wolfreys AM, Liu Y, Cortopassi G, Green MH, Arlett CF, et al. Frequencies of hprt(-) mutations and bcl-2 translocations in circulating human lymphocytes are correlated with United Kingdom sunlight records. Mutagenesis 1999;14:527-32. [PubMed: 10567026]

41. Roulland S, Lebailly P, Lecluse Y, Briand M, Pottier D, Gauduchon P. Characterization of the $\mathrm{t}(14 ; 18)$ BCL2-IGH translocation in farmers occupationally exposed to pesticides. Cancer Res 2004;64:2264-9. [PubMed: 15026372] 


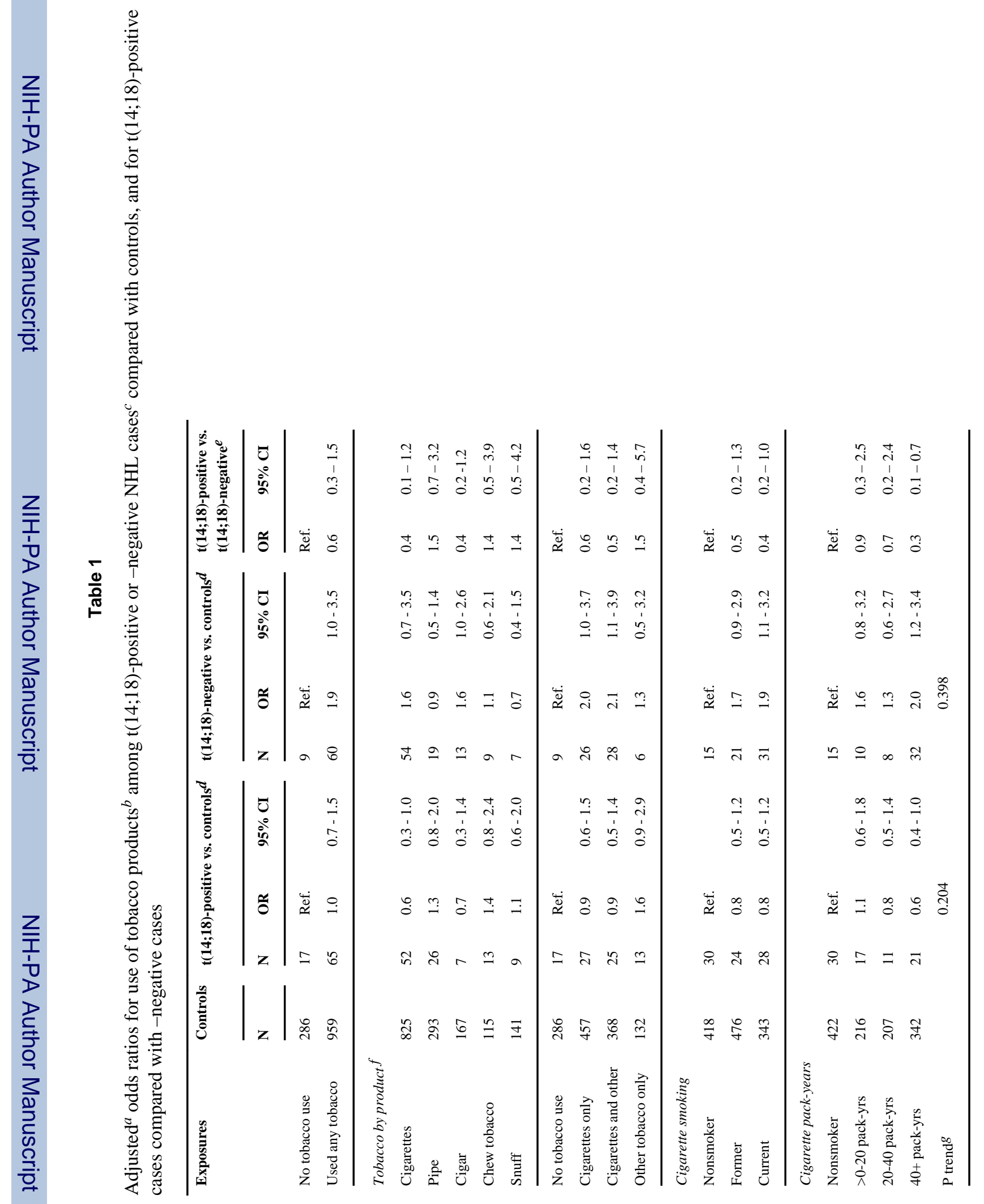


Chang et al.

Page 11

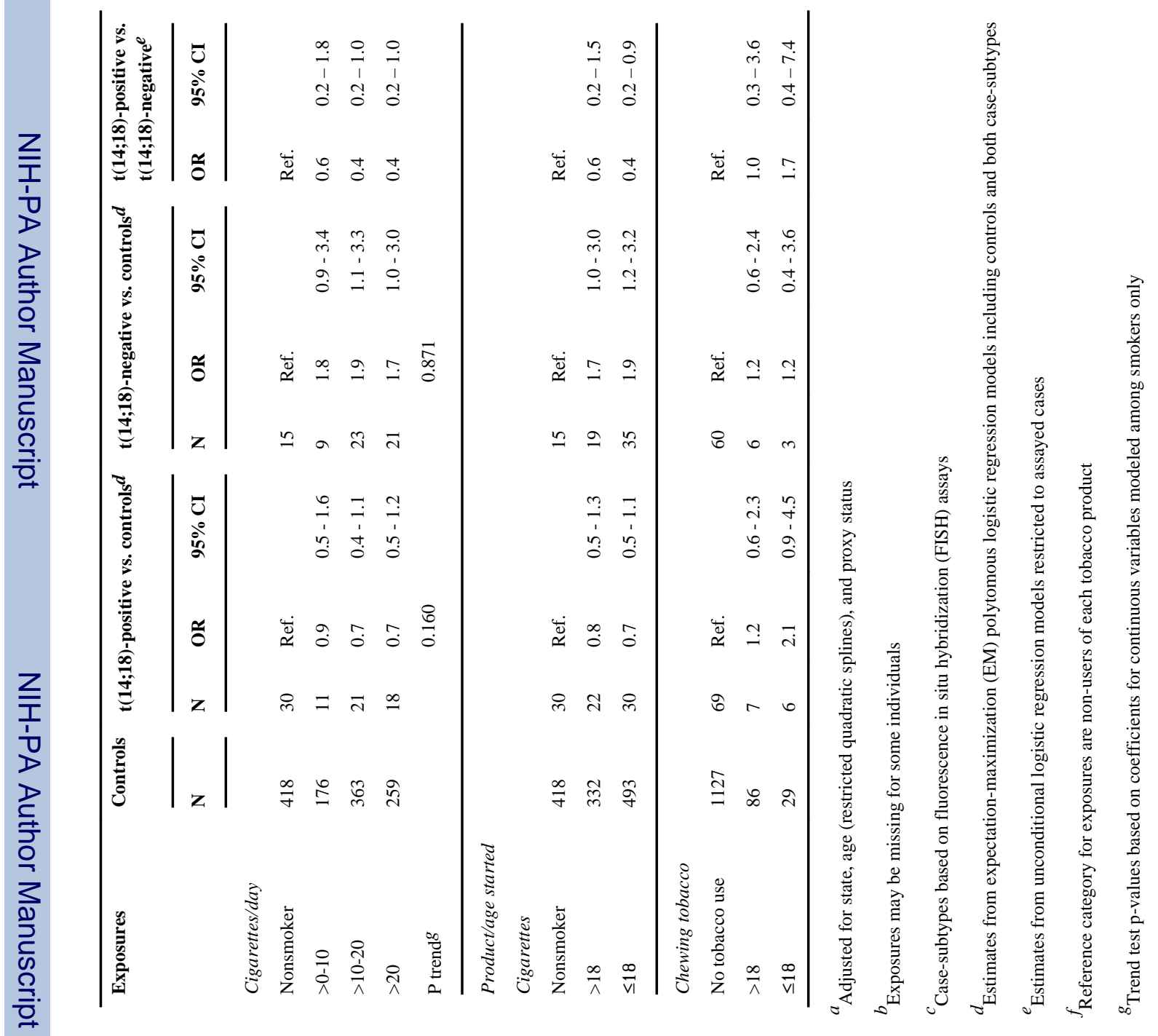

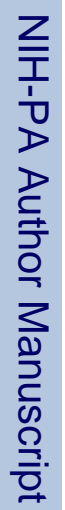

Cancer Causes Control. Author manuscript; available in PMC 2011 July 1. 


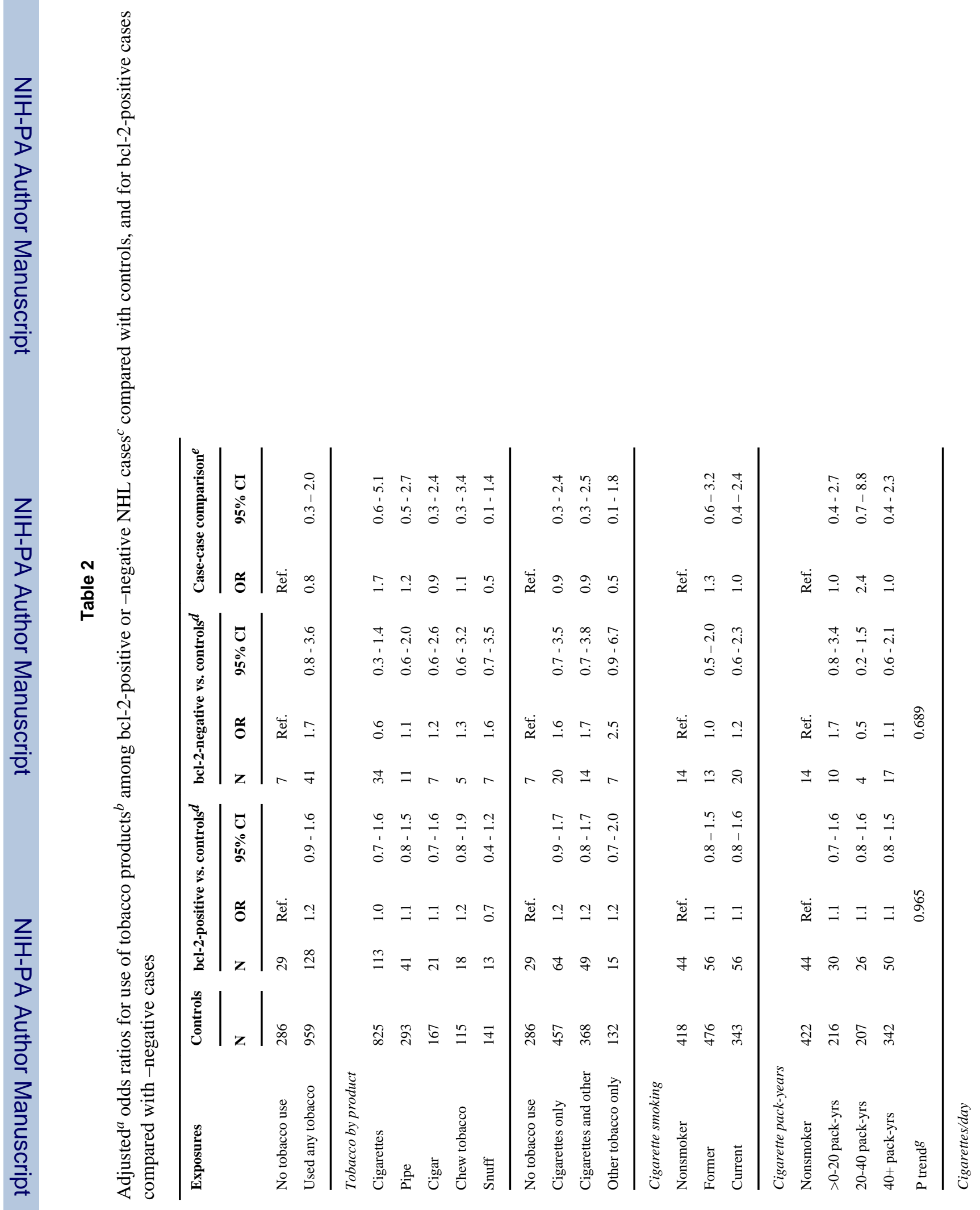




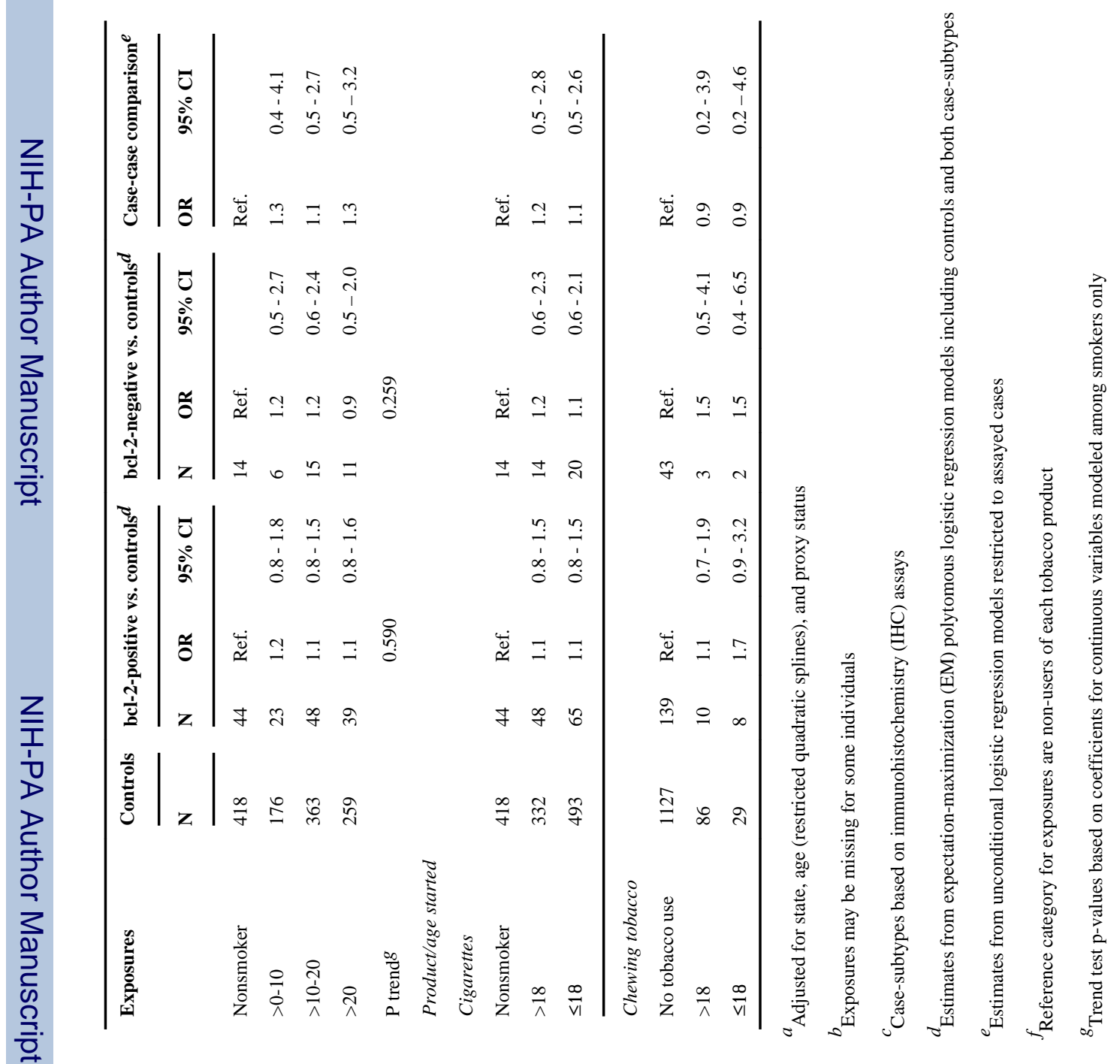




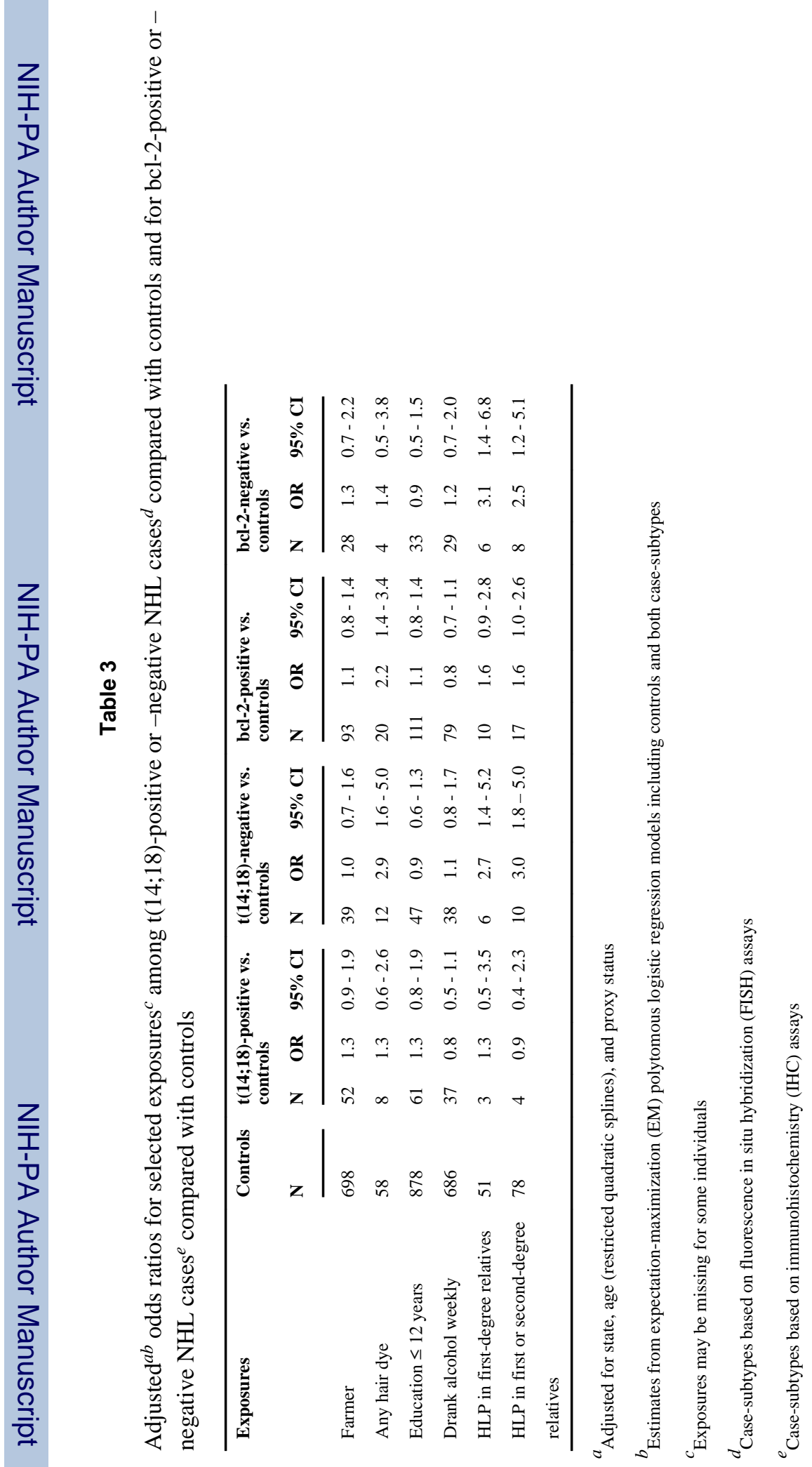

